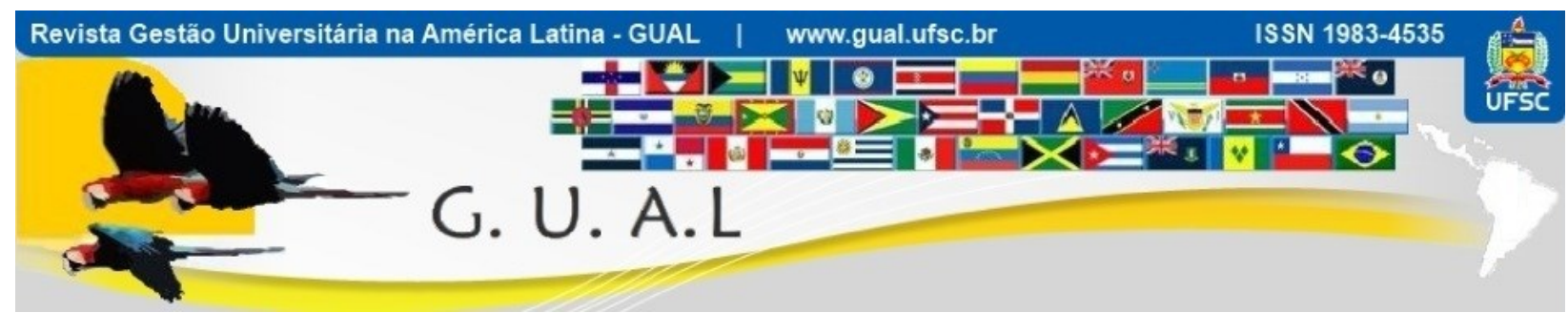

DOI: https://doi.org/10.5007/1983-4535.2021.e74998

\title{
ALINHAMENTO ENTRE CUSTOS, ORÇAMENTO E PLANEJAMENTO ESTRATÉGICO NO INSTITUTO FEDERAL DE EDUCAÇÃO, CIÊNCIA E TECNOLOGIA CATARINENSE
}

\section{ALIGNMENT BETWEEN COSTS, BUDGET AND STRATEGIC PLANNING AT THE FEDERAL INSTITUTE OF EDUCATION, SCIENCE AND TECHNOLOGY \\ CATARINENSE}

Eduardo Beeck Garozzi, Mestre http://orcid.org/0000-0002-3166-6003 edugarozzi@gmail.com

Instituto Federal de Educação, Ciência e Tecnologia Catarinense | Departamento de Administração e Planejamento Blumenau | Santa Catarina | Brasil

Fabiano Maury Raupp, Doutor http://orcid.org/0000-0001-9533-2574 fabianoraupp@hotmail.com

Universidade do Estado de Santa Catarina | Escola Superior de Administração e Gerência Florianópolis | Santa Catarina | Brasil

Recebido em 22/junho/2020

Aprovado em 05/outubro/2020

Publicado em 01/janeiro/2021

Sistema de Avaliação: Double Blind Review 


\title{
RESUMO
}

O artigo teve como objetivo analisar o alinhamento entre Custos, Orçamento e Planejamento Estratégico no Instituto Federal de Educação, Ciência e Tecnologia Catarinense. A pesquisa é de natureza qualitativa, com caráter descritivo e interpretativo. Para a coleta de dados realizou-se levantamento documental do Regimento Geral, Planejamento Estratégico, Plano de Desenvolvimento Institucional, Relatórios de Gestão e endereço eletrônico oficial da instituição. Também foi realizada entrevista com servidor da Diretoria de Administração e Planejamento da Reitoria, departamento responsável pelos processos orçamentários do Instituto. Após a coleta, foi realizada análise de conteúdo categorial. Cada Unidade é responsável pelo seu planejamento e execução, vinculadas ao PE institucional, bem como pela respectiva gestão orçamentária. Cada Unidade possui metodologia própria para gestão dos custos e execução das suas ações, atividades, projetos e programas internos, respeitando desta forma a autonomia de gestão em um modelo descentralizado. Cada Unidade adota métodos de apuração de custos conforme as demandas da gestão local para executar seus planejamentos internos. Portanto, analisar e avaliar conjuntamente PE, orçamento e os respectivos custos requer que a organização estruture suas informações neste intuito. A gestão estratégica de custos favorece a análise de alternativas, tomada de decisão e implementação do $\mathrm{PE}$ em contexto de instabilidade orçamentária. Assim, algumas diretrizes foram suscitadas no sentido de apontar caminhos para aprimoramento do alinhamento entre os elementos investigados.

Palavras-chave: Custos. Orçamento. Planejamento Estratégico. Educação Pública.

\begin{abstract}
The article aimed to analyze the alignment between Costs, Budget and Strategic Planning at the Federal Institute of Education, Science and Technology Catarinense. The research is of a qualitative nature, with a descriptive and interpretative character. For data collection, a documentary survey of the General Regulations, Strategic Planning, Institutional Development Plan, Management Reports and official website of the institution was carried out. An interview was also conducted with a member of the Rectory's Administration and Planning Direction, the department responsible for the Institute's budget processes. After collection, categorical content analysis was performed. Each Unit is responsible for its planning and execution, linked to the institutional Strategic Planning, as well as for the respective budget management. Each Unit has its own methodology for managing costs and executing its actions, activities, projects and internal programs, thus respecting management autonomy in a decentralized model. Each Unit adopts cost calculation methods according to the demands of the local management to execute its internal planning. Therefore, jointly analyzing and evaluating $\mathrm{PE}$, budget and respective costs requires the organization to structure its information for this purpose. Strategic cost management favors the analysis of alternatives, decision making and implementation of the Strategic Planning in a context of budgetary instability. Thus, some guidelines were raised in order to point out ways to improve the alignment between the elements investigated.
\end{abstract}

Keywords: Costs. Budget. Strategic Planning. Public Education. 


\section{INTRODUÇÃO}

Com a evolução das funções do orçamento público moderno a partir do século XX, passando de instrumento de controle político a um processo de integração planejamentoorçamento (KOHAMA, 2014), a adoção de sistemas de mensuração de custos ganhou crescente importância no setor público. O Orçamento-Programa, amplamente difundido como modelo base dos orçamentos modernos, demanda a incorporação da contabilidade de custos à contabilidade fiscal orçamentária devido à sua ênfase nos resultados e na determinação dos respectivos custos necessários para seu alcance (GIACOMONI, 2017). A utilização do cálculo de custos é fundamental ao modelo para a alocação dos recursos conforme as necessidades (DIAMOND, 2006).

A partir da década de 1990 os modelos orçamentários derivados do OrçamentoPrograma passam a enfatizar o desempenho no setor público, que deve ser medido considerando os resultados sob uma perspectiva mais ampla, por meio dos impactos que os produtos têm frente às necessidades sociais, resolução de problemas e desenvolvimento econômico-social. O sistema de custos nesse contexto contribui com a mensuração de subprogramas, atividades, projetos etc. traduzindo recursos consumidos em custo diretos ou indiretos, seguido pela sua alocação em atividades que integram os programas (DIAMOND, 2006). No setor público de maneira específica, além do suporte à tomada de decisão e controle gerencial, a contabilidade de custos contribui para a transparência (RAUPP, 2009). O autor aponta que a diferença da gestão de custos no setor público é sua orientação para o controle de desempenho de serviços e políticas públicas ao invés da apuração de lucros e avaliação de estoques, que ocorre no setor privado.

A outra "lente" do estudo, o Planejamento Estratégico, também é originário do setor privado, e desde a década de 1980 passou a ser estudado e incorporado ao setor público motivado pela escassez de recursos e pressão por eficiência na gestão pública, devendo ser reconhecidas as regras e as diferenças que regem as organizações públicas e privadas (RING; PERRY, 1985). A estratégia organizacional refere-se à determinação de objetivos de longo prazo, adoção de cursos de ação e alocação dos recursos necessários para sua realização (CHANDLER, 1962), ocorrendo de forma deliberada, formal e prescritiva, com foco em elementos como controle, orçamento, programas, e planos para seu desdobramento, segundo a escola do Planejamento Estratégico (MINTZBERG, 2004; MINTZBERG; AHLSTRAND; LAMPEL, 2010). Autores trabalham o tema no setor público, desde uma abordagem 
tradicional como Bryson (1988; 2004), Bryson, Anderson e Alston (2011), até uma abordagem situacional como Carlos Matus (1996; 2006). Elemento comum entre os modelos é a necessidade de alinhamento dos recursos à estratégia para sua implementação, alinhamento dos recursos este que pode ser potencializado pela gestão de custos. Clássica ferramenta de alinhamento estratégico no setor privado, o Balanced Scorecard, criado por Kaplan e Norton (1997) também apresenta modelo adaptado para o setor público, trazendo como foco a perspectiva do cliente, sendo esta representada pela sociedade (NIVEN, 2005).

Em um contexto onde a função de controle do orçamento ganha ênfase a partir do século XXI no Brasil (MANCINI, 2018), dispositivos como a Lei de Responsabilidade Fiscal (BRASIL, 2000) e o Novo Regime Fiscal (BRASIL, 2016) apresentam-se como alguns dos instrumentos em meio às reformas que visam conter a expansão dos custos públicos no país. Para o amadurecimento do processo orçamentário brasileiro, a gestão de custos é fundamental ao permitir sua evolução para um modelo orientado para o desempenho, por meio da avaliação de alcance de objetivos dos programas e eficiência das ações governamentais, bem como dos respectivos gastos para tanto (SANTOS; RAUPP; SECCHI, 2018).

O artigo apresenta os resultados do estudo de caso em instituição pública brasileira de educação, o Instituto Federal de Educação, Ciência e Tecnologia Catarinense, com o objetivo de analisar o alinhamento entre Custos, Orçamento e Planejamento Estratégico. Busca, desta forma, proporcionar o alinhamento dos recursos da instituição para o alcance de seus objetivos estratégicos, aprimoramento no seu desempenho e no seu processo orçamentário, oferecendo resposta aos desafios contextuais de limitações e controle fiscal. Após o capítulo introdutório, aborda-se referencial teórico sobre os temas "Custos no Setor Público" e "Planejamento Estratégico no Setor Público". Em seguida são apresentados os procedimentos metodológicos e a análise dos dados obtidos. Por fim apresentam-se as considerações finais.

\section{CUSTOS E ORÇAMENTO NO SETOR PÚBLICO}

Conforme a Resolução do Conselho Federal de Contabilidade $\mathrm{n}^{0} 1.366$, de 25 de novembro de 2011, que "estabelece a conceituação, o objeto, os objetivos e as regras básicas para mensuração e evidenciação dos custos no setor público" (CFC, 2011, p.2), custos são definidos como "gastos com bens ou serviços utilizados para a produção de outros bens ou serviços" (CFC, 2011, p. 5). No setor público, o subsistema de mensuração de custos tem como objetivos a mensuração, registro e evidenciação de custos de objetos diversos (produtos, 
serviços, programas, projetos, atividades, ações, órgãos, etc.), além do apoio à avaliação e melhoria de resultados e desempenhos, nas tomadas de decisão, nas funções de planejamento e orçamento, e no controle de custos e melhoria da qualidade do gasto (CFC, 2011).

No Orçamento-Programa, modelo base adotado pela Administração Pública Brasileira, a identificação dos insumos necessários para mensuração dos custos dos programas é um de seus elementos essenciais (GIACOMONI, 2017). Isto ocorre devido a necessidade de associar a mensuração física (realização, fins) à mensuração financeira (custo dos recursos, meios). Giacomoni (2017) classifica os custos em dois tipos: predeterminados e reais ou históricos. $\mathrm{Na}$ etapa de elaboração do orçamento encontram-se os custos predeterminados, podendo ser estimados ou padrão. Os custos estimados baseiam-se em previsão anterior à sua execução, valendo-se de metodologia que considera os custos históricos. Os custos padrão são determinados por estudos que consideram características específicas de determinado sistema produtivo. Nas fases de execução e controle obtém-se os custos reais, originando um histórico que pode auxiliar nas estimativas para o próximo ciclo orçamentário (GIACOMONI, 2017). Outros elementos essenciais do modelo são os objetivos e propósitos da instituição, para os quais serão alocados os recursos; os próprios programas, instrumentos de integração de esforços governamentais para atingir os objetivos, e; as medidas de desempenho (GIACOMONI, 2017).

A análise de alternativas necessárias para definição dos objetivos do programa, envolve a identificação dos meios alternativos para atingi-los, o exame e ponderação das alternativas, abrangendo elementos como custo com relação ao grau de contribuição de cada alternativa para o alcance dos objetivos (GIACOMONI, 2017). Santos, Raupp e Secchi (2018) observam que a análise das alternativas mais vantajosas para a sociedade é possibilitada pela mensuração dos custos, auxiliando na tomada de decisão dos gestores público. A tomada de decisão é auxiliada pelo fornecimento de dados e informações que possibilitam comparar valores efetivamente executados com o previsto, bem como a análise de consequências de curto, médio e longo prazo referente questões diversas pertinentes à gestão pública, como terceirizações, cortes, fixação de preços, produção interna ou compra de bens e serviços, dentre outras (MARTINS, 2008).

$\mathrm{Na}$ área da Educação no setor público, foco do presente estudo, Medeiros, Cerqueira e Neto (2014) afirmam que a gestão de custos se presta como ferramenta de planejamento institucional, e não apenas de racionalização de gastos. Atua como instrumento de natureza 
gerencial, para o fornecimento de informações a fim de subsidiar os processos de tomada de decisão, aumento da transparência e mensuração da relação custo/benefício, a fim de entregar os objetivos propostos pela instituição de forma mais eficiente diante da escassez de recursos e aumento de demanda, ou seja, "o maior benefício pelo menor custo à maior quantidade de cidadãos" (MEDEIROS; CERQUEIRA; NETO, 2014, p. 96). Lucas (2015) aponta que na área da educação, a utilização de metas, ações e os respectivos custos decorrentes do Plano de Metas Institucional pode melhorar o desempenho na alocação de recursos por meio do rompimento da prática do incrementalismo no orçamento, na qual os orçamentos são replicados ano após ano.

Em termos legais, a Lei Complementar $n^{\circ} 101$, de 4 de maio de 2.000, prevê em seu Art. 50, $\S 3^{\circ}$, que "a Administração Pública manterá sistema de custos que permita a avaliação e o acompanhamento da gestão orçamentária, financeira e patrimonial.” (BRASIL, 2000). Em âmbito federal, a Lei $\mathrm{n}^{\mathrm{o}}$ 10.180, de 6 de fevereiro de 2001, prevê a instituição do Sistema de Contabilidade Federal, definindo como uma de suas finalidade a evidenciação dos custos dos programas e das unidades da Administração Pública Federal. Posteriormente o Decreto $\mathrm{n}^{\mathrm{o}}$ 6.976, de 7 de outubro de 2009 regulamenta o Sistema de Contabilidade Federal, atribuindo ao órgão central deste, em seu Art. $7^{\circ}$ inc. XIX, competência pela manutenção de sistema de custos que permita a avaliação e o acompanhamento da gestão orçamentária, financeira e patrimonial (BRASIL, 2009). A Portaria $\mathrm{n}^{\mathrm{o}}$ 157, de 9 de março de 2011 cria o Sistema de Custos do Governo Federal, integrado pela Secretaria do Tesouro Nacional do Ministério da Fazenda, como órgão central e pelas unidades de gestão interna dos Ministérios e da Advocacia-Geral da União, como órgãos setoriais, responsáveis pelo acompanhamento de custos no Sistema de Informações de Custos - SIC (BRASIL, 2011).

O Sistema de Informação de Custos do Setor Público, aprovado pela Resolução n ${ }^{\circ}$ 1.366 de 25 de novembro de 2011 do Conselho Federal de Contabilidade, é apoiado em três elementos: sistema de acumulação; sistema de custeio e método de custeio. O sistema de acumulação refere-se a como os custos são acumulados e apropriados aos bens, serviços e demais objetos de custos estando relacionado ao fluxo físico e real da produção. O sistema de custeio refere-se ao modelo de mensuração, permitindo custear os diversos agentes de acumulação de acordo com diferentes unidades de medida (custo histórico, custo-corrente, custo estimado, e custo padrão), dependendo das necessidades dos tomadores de decisões. O método de custeio se refere ao método de apropriação de custos (direto, variável, por 
absorção, por atividade ou pleno) para sua identificação e associação ao respectivo objeto de custo (CFC, 2011). O Manual de Informações de Custos do Governo Federal diferencia conceitualmente ainda objetos de custos e centro de custos. Os objetos de custo "qualificam o que será medido (item) e a forma como será estruturada, acumulada e gerada a informação de custo, em conformidade com as necessidades estratégicas da gestão”. Já o Centro de Custos é definido como "a unidade mínima de acumulação de custos, tanto diretos como indiretos, onde são identificados o consumo efetivo do recurso e o beneficiário imediato do gasto, conforme estruturado na definição do que se deseja mensurar e avaliar (objeto de custo)" (BRASIL, 2018).

O método de custeio deve ser definido de acordo com a trajetória estratégica adotada pela organização, em busca das metas e objetivos priorizados (MEDEIROS; CERQUEIRA; NETO, 2014). Dentre os desafios identificados pelos autores para implantação de um sistema de custos em organização da Educação Pública está a relativa complexidade de uma estrutura de gestão descentralizada, multicampi, com uma ampla diversidade de cursos ofertados em diferentes municípios. Citam a necessidade de informatização de um sistema seguro de dados e da compatibilização e sincronia entre as áreas que desenvolvem atividades meio e atividades fim.

Diversos desafios são apontados por Giacomoni (2017) na aplicação dos modelos de apuração de custos, tais quais a resistência à mudanças, o tradicionalismo do setor público, a necessidade de procedimentos estatísticos extracontábeis, implantação progressiva para assimilação dos servidores, um desenvolvimento descentralizado ao contrário da contabilidade fiscal convencional, a necessidade de critérios adequados para o rateio de custos que afetam mais de um projeto, atividade ou centro de custos, e as despesas diferidas que ocorrem devido à peculiaridade das fases de empenho e liquidação existentes no serviço público, podendo ocorrer em exercícios diferentes. Santos, Raupp e Secchi (2018) afirmam que atualmente não há uma cultura de gestão de custos no serviço público brasileiro, na qual tanto governo como sociedade desconhecem os custos de tais serviços.

Superados esses desafios, observa-se que a gestão de custos no setor público pode proporcionar melhorias nos resultados das organizações, desempenho e qualidade do gasto, auxiliando os processos de tomada de decisão, planejamento, avaliação, controle e orçamento. Para tanto é importante que adotem sistemas e métodos alinhados à estratégia organizacional e aos seus objetivos, que possibilitem a mensuração dos objetos de interesse da gestão, tanto 
sob o aspecto físico como financeiro. Observa-se a utilização dos custos históricos (estimados ou padrão) no processo de planejamento e elaboração do orçamento e a determinação dos custos reais durante as etapas de execução e controle. Elementos que contribuem para tanto são os objetos de custos, centro de custos, medidas de desempenho e identificação de insumos que auxiliem a análise de alternativas. A informação presta importante papel neste processo, devendo ser útil para tanto, oportuna, confiável e comparável, devendo guardar relação favorável quanto ao custo de seu levantamento e seus benefícios. Observadas as principais contribuições e elementos da gestão de custos no setor público, bem como sua relação com a estratégia, planejamento e objetivos das organizações, aborda-se a seguir o Planejamento Estratégico no Setor Público.

\section{PLANEJAMENTO ESTRATÉGICO NO SETOR PÚBLICO}

O planejamento estratégico é apresentado por Mintzberg, Ahlstrand e Lampel (2010) como uma das dez escolas de pensamento sobre formulação de estratégia, caracterizado pelo caráter prescritivo, processo formal e deliberado. O modelo sugere o desdobramento hierárquico entre objetivos, orçamentos, estratégias e programas. Suas origens são associadas ao modelo seminal de Igor Ansoff em 1965 e posteriormente ao modelo de George Steiner em 1969, tendo seu auge durante a década de 1970 (MINTZBERG, 2004).

Desde a década de 1980 o planejamento estratégico ganha ênfase também no setor público, motivado pela escassez de recursos e pressão por eficiência na gestão pública (RING; PERRY, 1985). A distinção entre organizações públicas e privadas é objeto de crítica por autores seminais do tema, como Ansoff (1983), que observa que as empresas privadas são cada vez mais pressionadas a desempenhar atividades inerentemente sem fins lucrativos observando a ética social. Da mesma forma, organizações públicas sem fins lucrativos são pressionadas a buscar maior eficiência, sendo apontada a prática de um orçamento estratégico como um dos fatores para otimização de seu desempenho. Para tanto é necessário que além dos recursos necessários às operações, seja alocada parte dos recursos para o impulso estratégico das organizações (ANSOFF, 1983). O setor público trabalha o tema desde abordagens tradicionais adaptadas para o setor, como a de Bryson (1988; 2004), Bryson, Anderson e Alston (2011) até uma abordagem situacional como de Carlos Matus (1996; 2006).

A abordagem tradicional prevê a elaboração e implementação da estratégia 
organizacional em etapas. O modelo proposto por Bryson, Anderson e Alston (2011) traz um ciclo composto de cinco etapas principais: compreender a implementação e avaliar a prontidão da organização; organização para implementação; esclarecimento quanto às direções estratégicas e operacionais; estruturação e alocação de recursos para a implementação, alinhamento e aprendizado continuado; manutenção ou alteração do curso de implementação. O objetivo, tal qual do planejamento estratégico do setor privado, mantém-se em realizar a missão das organizações, sua estratégia e objetivos. Dentre as diferenças chave para o setor privado estão a necessidade de satisfação dos interesses de stakeholders num ambiente desvinculado de negócio, além de atender às obrigações legais, manter aprendizagem organizacional continuada e criação constante de valor público (BRYSON; ANDERSON; ALSTON, 2011).

$\mathrm{Na}$ abordagem situacional, o modelo apresentado por Carlos Matus (1996, 2006), concebe o planejamento estratégico como um jogo social, semicontrolado, descrito a partir da intersubjetividade entre os diferentes interesses, objetivos e perspectivas dos diversos atores envolvidos. Parte do princípio de aceitação da incerteza em um ambiente complexo, onde não se pode prever plenamente a ação de todos os atores, bem como os resultados que decorrem desta interação. Enfatiza o aspecto político em contrapartida ao controle determinístico e puramente técnico da planificação estratégica tradicional. A tomada de decisão em seu modelo baseia-se em uma racionalidade técnico-política, a partir da projeção de cenários, a depender do contexto situacional (MATUS, 2006).

No modelo de planificação situacional, assume-se a impossibilidade de se governar com total governabilidade do sistema e total capacidade de governo, devendo existir um equilíbrio dinâmico entre governabilidade, capacidade de governo e projeto de governo, o que Matus $(1996,2006)$ descreve como triângulo de governo. O projeto de governo refere-se aos objetivos do ator, a governabilidade diz respeito às variáveis que o governo controla ou não, enquanto a capacidade diz respeito a elementos como a perícia, métodos e qualidade presentes na gestão, administração e controle (MATUS, 1996; 2006).

No Planejamento Estratégico Situacional (PES) o plano é definido como um produto momentâneo do processo, dentro de uma cadeia de ações em busca dos objetivos (MATUS, 2006). O modelo atribui a responsabilidade do planejamento a quem governa, diferente do modelo tradicional onde a função de planejamento é separada. Diferencia-se ainda do planejamento tradicional ao trabalhar com a tecnologia de módulos (explicativos, de ação, de 
gestão e complementares) a serem combinados situacionalmente, o que the confere maior flexibilidade para adaptação ao contexto, ao invés de um plano rígido pré-definido. Dentre as vantagens da tecnologia de módulos apresentadas pelo autor, está a possibilidade de vinculação real do plano e do orçamento, ao caracterizar o plano como instrumento de organização para ação, com a definição de responsabilidades (MATUS, 2006).

A análise estratégica do PES envolve variáveis como: os atores/jogadores e os confrontos de interesses; a motivação e peso dos atores; as trajetórias, sequenciamento das ações; as operações do plano ou táticas, e; a estratégia para realização da jogada, seja por meio do uso de autoridade, cooptação, negociação, confronto ou dissuasão. Outro ponto central do modelo é a questão do poder, que é compreendido como um recurso escasso neste jogo social. A capacidade de ação de cada ator é limitada conforme o nível de controle sobre grandes grupos de recursos escassos, como: o poder político, referente ao controle dos centros de decisão; o poder econômico, referente ao controle de recursos econômicos e decisões orçamentárias; o poder comunicacional, referente ao controle de recursos comunicacionais, e; o poder cognitivo e organizativo, referente ao controle das capacidades científicas e técnicas (MATUS, 2006).

Observa-se em ambas as abordagens a questão dos recursos econômicos/orçamentários como elemento necessários à implementação da estratégica. $\mathrm{O}$ modelo situacional no entanto, enfatiza tanto o aspecto técnico quanto político na utilização dos recursos para a viabilidade estratégica do plano, e não apenas o aspecto técnico como no modelo tradicional. A análise das relações de poder e o capital político são enfatizados desta forma no PES.

O modelo de alinhamento estratégico, Balanced Scorecard (BSC), tem como objetivo traduzir e comunicar a visão e a estratégia institucional por toda organização, pelo seu desdobramento em objetivos, indicadores, metas e iniciativas. Utiliza o conceito de mapas estratégicos, que devem conter estes elementos e ser desdobrados por todos os níveis e setores, orientados pela estratégia central (KAPLAN; NORTON, 1997). No setor público é adaptado para enfatizar a perspectiva dos clientes (sociedade) como objetivo principal das organizações. A perspectiva financeira é adaptada para dar sustentação às demais perspectivas estratégicas, focando na otimização orçamentária (NIVEN, 2005). 


\section{PROCEDIMENTOS METODOLÓGICOS}

A presente pesquisa é de natureza qualitativa, objetivando analisar o alinhamento entre Custos, Orçamento e Planejamento Estratégico no Instituto Federal de Educação, Ciência e Tecnologia Catarinense (IFC), a partir de estudo de caso na organização. Seu objetivo possui caráter descritivo e interpretativo. Na etapa descrita foram descritos inicialmente a gestão de custos, orçamento e planejamento estratégico da organização. Na etapa interpretativa foram analisados à luz do referencial os principais elementos referentes ao alinhamento entre Custos, Orçamento e Planejamento Estratégico, observados na organização.

Para a coleta de dados realizou-se levantamento documental do Regimento Geral, Planejamento Estratégico, Plano de Desenvolvimento Institucional, Relatórios de Gestão e endereço eletrônico oficial da instituição. Também foi realizada entrevista com servidor da Diretoria de Administração e Planejamento da Reitoria, departamento responsável pelos processos orçamentários do Instituto. Após a coleta, foi realizada análise de conteúdo categorial (BARDIN, 2004) abordando os principais temas trazidos no referencial, como: objetivos, programas, tomada de decisão, planejamento, avaliação, controle, orçamento, sistemas e métodos de custos, mensuração física e financeira, objetos e centros de custos, medidas de desempenho, identificação de insumos, análise de alternativas e estrutura de informações.

Após a análise, foi possível identificar como estes fatores se apresentam na organização, como estão alinhados e quais são as oportunidades de melhoria. A partir desta análise e com base no referencial teórico, inferiu-se sobre o alinhamento entre Custos, Orçamento e Planejamento Estratégico no IFC.

\section{APRESENTAÇÃO E ANÁLISE DE RESULTADOS}

\subsection{O PLANEJAMENTO ESTRATÉGICO DO IFC}

O IFC caracteriza-se como instituição de educação superior, básica e profissional, pluricurricular e multicampi, especializada na oferta de educação profissional e tecnológica nas diferentes modalidades de ensino, com base na conjugação de conhecimentos técnicos e tecnológicos com as suas práticas pedagógicas. É instituição dotada de autonomia administrativa, patrimonial, financeira, didático-pedagógica e disciplinar, conforme a sua lei de criação (BRASIL, 2008). Ente da administração pública federal indireta, possui dentre outras premissas, autonomia administrativa e financeira, condicionadas às normas que 


\section{ALINHAMENTO ENTRE CUSTOS, ORÇAMENTO E PLANEJAMENTO ESTRATÉGICO NO INSTITUTO FEDERAL DE EDUCAÇÃO, CIÊNCIA E TECNOLOGIA CATARINENSE \\ DOI: https://doi.org/10.5007/1983-4535.2021.e74998}

regulamentam a Administração Pública Federal, tais quais legislação geral sobre licitações e contratos, direito financeiro para elaboração e controle de orçamentos e balanços, regime jurídico dos servidores públicos, dentre outras.

Dentre seus documentos norteadores, a organização adota o Planejamento Estratégico (PE). Sua primeira versão compreendia o período de 2013 a 2017, sendo recentemente publicado o documento para o período de 2018 a 2021. A nova versão enfatiza o desenvolvimento e articulação da prática da gestão institucional integrada, desdobrada em objetivos como o fomento da cultura da gestão estratégica e do planejamento e otimização da gestão orçamentária integrada. A missão do IFC expressa no PE, em consonância com as finalidades previstas em sua lei de criação, é: "Proporcionar educação profissional, atuando em Ensino, Pesquisa e Extensão, comprometida com a formação cidadã, a inclusão social, a inovação e o desenvolvimento regional” (IFC, 2018a, p.9). Como visão, o PE da instituição declara: "Ser referência nacional em educação profissional, científica e tecnológica, para o mundo do trabalho, por meio da formação cidadã" (IFC, 2018a, p.10).

O PE 2018-2021 apresenta-se como Mapa Estratégico contendo missão, visão e 10 objetivos estratégicos distribuídos em 3 perspectivas: Sociedade, Processos Internos, Crescimento e Aprendizado. O documento apresenta também 8 valores da instituição: ética; credibilidade; transparência; justiça social; excelência; sustentabilidade; formação cidadã; qualidade de ensino, pesquisa e extensão. Cada um dos 10 objetivos estratégicos desdobra-se em objetivos táticos no documento do $\mathrm{PE}$, totalizando 43 objetivos táticos. O PE apresenta rol de indicadores relacionados diretamente a cada um dos 10 objetivos estratégicos, apontando metas globais a serem atingidas no período do PE (algumas metas anuais e outras globais para o período). As metas para cada indicador variam desde percentuais (de valores orçamentários a serem alocados em ações, de adequação de infraestrutura, de redução de índices de evasão, de vagas ofertadas, de beneficiários de ações etc.), a quantitativos (de ações, projetos, publicações, produção científica, processos, oferta de cursos, beneficiários de ações etc.) e até mesmo metas qualitativas como: elaborar e aprovar diretrizes, seguir a priorização de obras, atualizar relatório de acessibilidade etc.

Quanto ao monitoramento e acompanhamento dos objetivos e metas, o documento do PE 2018-2021 prevê mecanismos como reuniões, alinhamentos e atualização constante do atingimento das ações definidas, com a publicização dos resultados no site institucional. A publicização do acompanhamento do PE se dá com a apresentação do Status PE anual de cada 
Campus no endereço eletrônico oficial do IFC. Este documento apresenta o status de atendimento às metas globais de cada objetivo estratégico do PE pelos Campi, bem como o detalhamento e justificativa de atendimento às metas. Não se verificou o status de execução dos planos operacionais individualizados de cada Campus. Outro documento que permite acompanhar o estado de implementação do PE é o Relatório de Gestão do IFC, o qual em sua versão de 2018 apresenta capítulo de destaque para PE e Governança. Dentre os desafios e incertezas para atingimento das metas do PE, descritos no documento, encontra-se a questão orçamentária, a Emenda Constitucional no 95 de 15 de dezembro de 2016, frequente contingenciamento, vulnerabilidade às políticas de governo e morosidade de acesso aos recursos orçamentários (IFC, 2019a).

\subsection{ORÇAMENTAÇÃO NO IFC}

A estruturação para implementação do $\mathrm{PE}$, devido à autonomia administrativa de cada Unidade, ficou sob competência das gestões locais, as quais desenvolveram seus próprios planos operacionais. Estes são elaborados pela gestão de cada Unidade, alinhados ao PE institucional, definindo em seu conteúdo os responsáveis em cada ação, objetivos operacionais, metas, indicadores e período de execução. Não foi identificado nos planos de ação a orçamentação para sua execução, identificação de insumos necessários e apuração dos custos.

O Entrevistado, que atua na Diretoria de Administração e Planejamento da Reitoria, unidade responsável pela maior parte das competências em todas as etapas processo orçamentário do IFC, explica que o orçamento da instituição é uma peça única, embora haja autonomia de cada uma de suas Unidades Gestoras no planejamento e execução. Este por sua vez integra o orçamento geral da Secretaria de Educação Profissional e Tecnológica (SETEC) ao qual está vinculado o IFC. O orçamento da SETEC representa parte do orçamento do Ministério da Educação (MEC), o qual divide os valores disponibilizados pelo Ministério da Economia entre as suas secretarias conforme as prioridades de governo.

A distribuição orçamentária entre todos os entes da Rede Federal é realizada conforme matriz orçamentária do Conselho Nacional das Instituições da Rede Federal de Educação Profissional, Científica e Tecnológica (CONIF), levando em consideração uma série de fatores como o número de alunos matriculados, o peso e o tempo de duração dos cursos, dentre outros fatores. Na distribuição interna dos recursos, o IFC respeita os valores trazidos 


\section{ALINHAMENTO ENTRE CUSTOS, ORÇAMENTO E PLANEJAMENTO ESTRATÉGICO NO INSTITUTO \\ FEDERAL DE EDUCAÇÃO, CIÊNCIA E TECNOLOGIA CATARINENSE \\ DOI: https://doi.org/10.5007/1983-4535.2021.e74998}

na matriz orçamentária do CONIF, repassando o respectivo valor de cada Campi, conforme a sua contribuição no cálculo do montante total do IFC (IFC, 2019b).

O Regimento Geral prevê a elaboração da proposta orçamentária anual pela PróReitoria de Administração, com base em elementos coletados junto à Reitoria e Campi, nos planos de desenvolvimento institucional, nos planos da gestão para o exercício e nas diretrizes do governo federal. Aos Campi compete anualmente a apresentação de proposta orçamentária à Reitoria, por meio de sua Direção-Geral, com a discriminação da receita e despesa previstas para a Unidade, conforme seu Art. 125 (IFC, 2018b). Observa-se, portanto, a caracterização do orçamento no IFC como um instrumento de planejamento, elaborado em conformidade com documentos orientadores da organização, sem referência explícita de sua vinculação com o Planejamento Estratégico, no entanto.

Na elaboração e planejamento orçamentário, o Regimento Geral prevê a participação de setores responsáveis por áreas diversas da instituição, conforme suas demandas, tais quais: TI, Gestão de Pessoas, Projetos de Obras, Bibliotecas, Extensão. Observa-se a existência de dois Órgãos colegiados que participam do processo, exercendo a apreciação e recomendações quanto ao orçamento do IFC: o Conselho Superior e o Colégio de Dirigentes (CODIR). Apesar do caráter consultivo, o CODIR é o âmbito onde ocorrem as deliberações e definições quanto ao processo orçamentário à nível institucional. Nos Campi a maior parte das competências é atribuída ao Departamento de Administração e Planejamento, desde o planejamento, coordenação, supervisão e avaliação do orçamento, elaborando e consolidando a proposta orçamentária anual que será encaminhada à Reitoria por meio da Direção-Geral da Unidade posteriormente. Participam do processo também a Diretoria de Desenvolvimento Educacional, acompanhando e participando da gestão orçamentária e a Coordenação de Extensão, na aplicação e fiscalização dos recursos destinados ao setor. Cada Campus possui também seu Órgão colegiado, o Conselho de Campus, de caráter consultivo, que dentre suas atribuições apoia o processo decisório e a gestão orçamentária da sua Unidade (IFC, 2018b).

\subsection{CUSTOS, ORÇAMENTO E PLANEJAMENTO NO IFC}

O acompanhamento da execução orçamentária durante o exercício, sob uma visão institucional, é realizada pela Diretoria de Administração e Planejamento da Reitoria, explica o Entrevistado. São analisados ao longo do ano os percentuais de execução de cada Campus dos créditos descentralizados, bem como a relação entre os valores empenhados (executados) 
e liquidados, quando é verificado o direito adquirido pelo credor, para o qual o crédito orçamentário foi empenhado, por meio da comprovação de entrega de material, prestação de serviço, cumprimento contratual (BRASIL, 1964). Segundo o Manual de Informações de Custos do Governo Federal, o momento de liquidação da despesa é a base para se chegar à informação ideal de custos (BRASIL,2018).

Para o Entrevistado, o desafio na execução do planejamento consiste em "não ter certeza de quanto e quando os valores serão efetivamente disponibilizados". Os limites orçamentários representam uma expectativa de valores a receber, podendo haver cortes, além dos contingenciamentos ao longo do ano que são comuns. Ainda que os valores sejam recebidos integralmente, esta incerteza obriga a instituição a adaptar o planejamento constantemente durante o ano, contingenciando também a execução de suas atividades e projetos. O Entrevistado explica que muitos eventos, visitas técnicas, capacitações, licitações que demandam um planejamento prévio deixam de ser realizados em função desta disponibilização tardia dos créditos orçamentários.

O Entrevistado explica que a mesma análise quanto à execução do orçamento é realizada pela Diretoria de Administração e Planejamento da Reitoria ao final do ciclo orçamentário também, subsidiando a gestão do IFC com informações para auxiliar a elaboração e execução dos próximos orçamentos. Ações ou Unidades que tiveram baixa execução no exercício anterior podem ser objeto de discussão para que haja remanejamento de créditos para outras Ações ou Unidades com maior demanda. Segundo ele estas são as principais ações de controle e avaliação internas, tanto durante a execução como ao término do processo. O principal instrumento para tanto são relatórios extraídos do Tesouro Gerencial, sistema integrado ao Sistema Integrado de Administração Financeira do Governo Federal (SIAFI).

Até o exercício de 2017, os Relatórios de Gestão do IFC apresentavam a prestação de contas orçamentária sob um aspecto predominantemente técnico e legal. O item 3.3 do Relatório de Gestão 2017, por exemplo, responsável pelo Desempenho Orçamentário da instituição, se estende por 38 páginas apresentando informações detalhadas quanto: execução física e financeira das ações da LOA; restos a pagar; execução descentralizada com transferência de recursos; realização de receitas; execução de despesas; suprimento de fundos, dentre outras (IFC, 2018c). A execução de despesas era apresentada por meio de tabelas trazendo série de valores subdivididos por modalidades de contratação (pregão eletrônico, 
concorrência, inexigibilidade, dispensa, etc.) grupos de despesa (despesas com pessoal, outras despesas correntes, investimentos), e; elementos de despesa (vencimentos e vantagens fixas, obrigações patronais, locação de mão-de-obra, material de consumo, obras e instalações etc.). A Apresentação e Análise de Indicadores de Desempenho do IFC, por exemplo, demonstrava 4 indicadores relacionados ao seu orçamento, em conformidade com o Acórdão do TCU $n^{\circ}$ 2.267 de 13 de dezembro de 2005.

A partir do Relatório de Gestão 2018, o IFC adotou novo modelo para o documento, o qual apresenta seção específica denominada Alocação de Recursos e Áreas Especiais da Gestão. A apresentação do orçamento ocorre de forma mais sucinta, com montantes totais e discriminação dos valores relacionados à capacitação, publicidade, ajuda de custo para moradia, funcionamento, emendas individuais, TEDs, assistência estudantil e gasto corrente por matrícula. Os dados são apresentados em séries históricas desde 2016 (com exceção dos gastos correntes por matrícula).

Os valores não se apresentam vinculados às Ações Orçamentárias, com o detalhamento dos respectivos objetivos, metas e indicadores orçamentários. Em contrapartida ao aspecto mais técnico dos Relatórios de Gestão até 2017, observa-se uma ênfase na apresentação dos resultados a partir de 2018. A análise crítica que buscava explicar a evolução dos valores e indicadores em si no modelo anterior é substituída por uma apresentação da Pró-Reitoria de Administração dos resultados obtidos nas ações, projetos e programas internos do IFC (não se confundem com as Ações e Programas Orçamentários do PPA e LOA). A seção apresenta ainda, quanto ao orçamento, relação de valores empenhados e liquidados por natureza de despesa.

Observa-se que a análise dos valores orçamentários por si fica em segundo plano, destacando-se a análise dos resultados. Como exemplo, são apresentados os montantes de recursos aplicados em TI, resumindo o total de investimentos $(\mathrm{R} \$ 370.677,97 \mathrm{em} \mathrm{2017}$; R\$ 1.229.676,40 em 2018) e custeio ( $\mathrm{R} \$ 351.076,87 \mathrm{em} \mathrm{2017}$; R 313.667,58 em 2018). Em seguida de forma mais extensa são descritas as principais contratações (solução de backup R\$ 549.600,00; parque computacional - R\$ 352.500,00; sistema integrado de gestão - R \$ 128.760,00), detalhando o objetivo destas, sua importância para a instituição, os principais beneficiados, além das principais iniciativas e resultados da TI para o ensino, pesquisa, extensão e gestão (IFC, 2019a). Em diversas outras seções do Relatório de Gestão 2018 observa-se esta ênfase na apresentação de resultados, com a indicação dos respectivos 
recursos alocados para tanto. Na seção de programas, projetos e ações de ensino, pesquisa e extensão, por exemplo, consta a relação entre o montante de valores alocados em programas específicos e seus produtos, como quantitativo de bolsas concedidas, de projetos contemplados, de registros de propriedade intelectual, dentre outros.

\subsection{DISCUSSÕES}

Observa-se que a organização possui seus objetivos estratégicos definidos em mapa estratégico, desdobrados hierarquicamente em objetivos táticos e planos operacionais de cada Unidade, com as respectivas metas, período, indicadores e responsáveis, conforme modelo de alinhamento estratégico sugerido pelo referencial (KAPLAN; NORTON, 1997; NIVEN, 2005). A estrutura de custos institucional identificada, aponta como objetos de custos alguns elementos programáticos, como ações orçamentárias e grupos de despesa, e outros de aspecto geral da gestão. A vinculação das informações de recursos para o atingimento de cada objetivo descrito nos planos de ação é importante elemento para sua execução, conforme sugerem autores de diversas abordagens sobre o PE (CHANDLER, 1962; MINTZBERG, 2004; MATUS, 2006; MINTZBERG; AHLSTRAND; LAMPEL, 2010, BRYSON; ANDERSON; ALSTON, 2011). A estrutura de custos na organização pode contribuir neste sentido ao vincular objetos de custos aos objetivos previstos no PE, bem como utilizar centros de custos que registrem a mensuração financeira das etapas necessárias para atingi-los, atendendo assim às necessidades estratégicas da gestão (BRASIL, 2018).

A inclusão de uma perspectiva financeira ao PE, não identificada no PE 2018-2021 da instituição, pode contribuir também para o alinhamento entre custos, orçamento e Planejamento Estratégico no IFC. Embora a perspectiva não seja o foco em organizações do setor público, devendo manter-se a ênfase nos objetivos voltados à sociedade, ela caracterizase como base do mapa estratégico, sustentando a implementação dos objetivos previstos nas demais perspectivas (NIVEN, 2005). A perspectiva financeira pode contemplar objetivos orientados para a otimização de custos operacionais, estruturação da gestão de custos no IFC, orçamentação estratégica para implementação do PE, dentre outros. Contribui ao abordar a gestão de custos e orçamentária sob perspectiva estratégica, integrada ao PE.

À nível institucional, verifica-se a prática de apuração de custos históricos totais para cada Unidade e para algumas ações internas, por meio dos relatórios do sistema Tesouro Gerencial extraídos pela Reitoria. Tal sistema de custeio (CFC, 2011) subsidia tanto 
discussões entre Gestão e Dirigentes de Campus para ajustes orçamentários ao longo do exercício, como estimativas de custos para elaboração de orçamentos futuros, auxiliando desta forma no próximo ciclo orçamentário conforme sugere Giacomoni (2017). As informações que fundamentam os processos de tomada de decisão orçamentária utilizam portanto dados de custos gerais comuns entre as Unidades e comparáveis entre estas. É possível comparar custos entre programas e ações que sejam comuns a mais de uma Unidade, como aqueles previstos na estrutura de custos institucional por exemplo, ou de execução institucional. Neste sentido a vinculação de informações de custos a objetivos estratégicos pode tornar mensurável e comparável também o esforço necessário à sua implementação entre as Unidades, favorecendo a análise de alternativas (SANTOS; RAUPP; SECCHI, 2018). É importante para tanto que tal qual o custo operacional das Unidades, os objetivos estratégicos também sejam objetos de custo na instituição, vinculando assim a alocação de recursos aos objetivos da organização, importante característica do Orçamento-Programa (DIAMOND, 2006; GIACOMONI, 2017).

A estruturação dos objetos e centros de custos orientados pelos objetivos estratégicos pode contribuir no alinhamento do orçamento para implementar o PE. Sendo os objetivos estratégicos elementos comuns à todas as Unidades a partir dos quais elaboram seus planos operacionais, a informação de custos referente às ações desenvolvidas em cada Campus para atingir seus objetivos favorece a comparação entre alternativas (GIACOMONI, 2017; SANTOS, RAUPP; SECCHI, 2018), permitindo o compartilhamento e adoção das melhores práticas. O modelo de gestão descentralizado contribui conforme a possibilidade de compartilhar e comparar entre as Unidades informações sobre custos para atingir objetivos em comum. O cenário de instabilidade, evidenciado pelos frequentes contingenciamentos e incertezas orçamentárias, demanda que a organização trabalhe seu planejamento a partir de análise de cenários conforme sugere Matus (1996; 2006). Neste sentido, o compartilhamento e comparação de alternativas e seus respectivos custos contribui na adaptação do planejamento e nas tomadas de decisão (SANTOS; RAUPP; SECCHI, 2018).

A mensuração física é apresentada com uma crescente ênfase em resultados nos Relatórios de Gestão, relacionando os valores alocados em cada área da gestão do IFC aos respectivos resultados das ações internas, programas, atividades e projetos desenvolvidos. Esta ênfase vai de encontro à evolução nos modelos orçamentários modernos (DIAMOND, 2006; GIACOMONI, 2017). Permite a evolução do processo orçamentário de um modelo 
incremental para um modelo orientado para resultados e desempenho. Os indicadores apresentados geralmente referem-se a quantidade de alunos beneficiários, de bolsas concedidas, de registros de propriedade intelectual, ou sob uma perspectiva mais qualitativa, apresentando de forma geral as principais soluções contratadas e realizações dos setores. As unidades de produto (quantidade de matrículas, bolsas etc.) portanto, são apresentadas majoritariamente como unidades de produto final a partir do Relatório de Gestão 2018, buscando refletir a eficácia da instituição. A distinção entre produto intermediário ou final é complexa, pois depende da análise do contexto estratégico mais amplo. Ações como aquisição de soluções de backup, parque computacional e sistema integrado de gestão são apresentados como resultados da gestão, podendo ser considerados como produtos finais caso a gestão os entenda como objetivos estratégicos da instituição, ou intermediários, caso sejam entendidos como meios para atingir objetivos estratégicos. Portanto é importante a vinculação dos resultados aos objetivos estratégicos para contextualização estratégica da informação apresentada, possibilitando uma análise da relação entre objetivos, ações/programas/projetos, resultados e os respectivos custos/valores. A estruturação das informações desta forma contribui para aprimorar tanto a transparência na prestação de contas, como a tomada de decisão para o planejamento e elaboração de orçamentos futuros.

\section{CONSIDERAÇÕES FINAIS E PROPOSIÇÃO DE DIRETRIZES}

O orçamento do Ministério da Educação é definido em função dos objetivos e prioridades de governo, o qual distribui o montante entre suas Secretarias conforme os objetivos e prioridades para a área. O orçamento do IFC usualmente é distribuído por meio de matriz acordada no CONIF, em função de critérios que remetem a uma estimativa de custos operacionais para funcionamento de cada instituição, tal como quantidade de alunos, peso e duração dos cursos, dentre outros. No entanto, os objetivos do IFC não se limitam ao quantitativo de alunos e gerenciamento dos respectivos custos operacionais para funcionamento. Seus objetivos contemplam ampla dimensão qualitativa e um caráter estratégico complexo, inerente às organizações da área da educação. Sua gestão de custos deve possibilitar ao mesmo tempo a otimização dos custos operacionais de funcionamento e a alocação orçamentária de recursos para seu impulso estratégico. Aprimorar seu desempenho e controlar custos não objetiva aferição de lucro ou contração orçamentária, mas aumentar a capacidade de recursos para atingir seus objetivos estratégicos. 


\section{ALINHAMENTO ENTRE CUSTOS, ORÇAMENTO E PLANEJAMENTO ESTRATÉGICO NO INSTITUTO FEDERAL DE EDUCAÇÃO, CIÊNCIA E TECNOLOGIA CATARINENSE \\ DOI: https://doi.org/10.5007/1983-4535.2021.e74998}

Cada Unidade é responsável pelo seu planejamento e execução, vinculadas ao PE institucional, bem como pela respectiva gestão orçamentária. Cada Unidade possui metodologia própria para gestão dos custos e execução das suas ações, atividades, projetos e programas internos, respeitando desta forma a autonomia de gestão em um modelo descentralizado. Não há uma sistemática de custos padrão formalizada na instituição. Cada Unidade adota métodos de apuração de custos conforme as demandas da gestão local para executar seus planejamentos internos. Tal modelo de gestão descentralizada pode contribuir tanto com o processo orçamentário, como na implementação do Planejamento Estratégico, conforme haja o compartilhamento de informações, comparação de alternativas e custos entre as Unidades e adoção das melhores práticas identificadas. Analisar e avaliar conjuntamente Planejamento Estratégico, orçamento e os respectivos custos requer que a organização estruture suas informações neste intuito.

O acompanhamento e avaliação do orçamento realizado a nível institucional enfatiza a análise dos valores disponíveis, empenhados e liquidados. O sistema Tesouro Gerencial utilizado possibilita esta análise a partir dos elementos programáticos como, por exemplo, Programas e Ações Orçamentárias, grupos e naturezas de despesa. Não agrega, no entanto, os objetivos estratégico da organização. Um desafio portanto está em consolidar tanto dados qualitativos (resultados e produtos), quanto seus custos, metas, prazos, indicadores de desempenho, insumos necessários, em uma estrutura de informação útil ao processo decisório, de forma oportuna, confiável, comparável e com uma relação favorável de benefícios em relação ao próprio custo de implantação. O processo de tomada de decisão pode ser aprimorado na medida em que as informações sejam estruturadas desta forma, considerando a necessidade de ajustes constantes no planejamento, remanejamentos e ajustes orçamentários. Para tanto, foram suscitadas algumas diretrizes, no intuito de aprimorar o alinhamento analisado na presente pesquisa, conforme segue:

- Transição gradual de um modelo orçamentário incremental para um modelo orientado por resultados: desenvolvimento de pessoas e processos para uma gestão estratégica, com ênfase na implantação dos objetivos previstos no PE da organização, considerando a mensuração de resultados, produtos, metas, prazos, indicadores de desempenho, insumos necessários e custos para tanto;

- Adoção de perspectiva financeira como base do mapa estratégico, dando suporte à implementação dos objetivos estratégicos previstos nas demais perspectivas;

- Estruturação de Objetos e Centros de Custos orientados para a melhoria de 
desempenho operacional e atingimento dos Objetivos Estratégicos;

- Estruturação de informações buscando a consolidação de dados sobre objetivos estratégicos, resultados, produtos, metas, prazos, indicadores de desempenho, insumos necessários e custos: deve possibilitar mensuração e análise destes elementos, sua comparação (entre Unidades, períodos, alternativas, etc.), fornecendo dados úteis e confiáveis à tomada de decisão e à prestação de contas junto à sociedade;

- Compartilhamento de alternativas estratégicas para execução do PE e melhores práticas orçamentárias e de gestão de custos entre as Unidades: estruturação de processos, equipes e informações de forma a favorecer a análise de cenários e de alternativas, considerando seus custos e disponibilidade orçamentária, no intuito de aprimorar o desempenho operacional e alcançar os Objetivos Estratégicos.

Conclui-se que uma gestão estratégica de custos favorece a análise de alternativas, tomada de decisão e implementação do PE em um contexto de instabilidade orçamentária. Pressupõe-se que a adoção das diretrizes citadas poderá aperfeiçoar o alinhamento entre Custos, Orçamento e Planejamento Estratégico no IFC. Entretanto, tem-se o entendimento de que a análise é de aspecto geral sobre o tema na instituição. A efetiva implementação dependerá de análise quanto à viabilidade, pesquisando em profundidade o complexo rol de fatores internos e externos à organização, tais como: seus sistemas de informação, sistemas gerenciais, estrutura de pessoal, competências, cultura organizacional, processo estratégico, contexto político e econômico, dentre outros. Assim, trabalhos futuros são encorajados para que possam investigar uma ou mais diretrizes no sentido de apontar caminhos para um aprimoramento do alinhamento entre os elementos investigados.

\section{REFERENCIAS}

ANSOFF, H. Igor. Administração Estratégica. São Paulo: Atlas, 1983.

BARDIN, L. Análise de conteúdo. São Paulo: Edições 70, 2004.

BRASIL. Lei Complementar $n^{0}$ 101, de 4 de maio de 2000. Estabelece normas de finanças públicas voltadas para a responsabilidade na gestão fiscal e dá outras providências. Diário Oficial da União, Brasília, 5 maio 2000. Disponível em: $<$ http://www.planalto.gov.br/ccivil_03/LEIS/LCP/Lcp101.htm> Acesso em: 26 mar. 2020.

BRASIL. Lei $\mathbf{n}^{\mathbf{0}} \mathbf{1 0 . 1 8 0}$, de 6 de fevereiro de 2001. Organiza e disciplina os Sistemas de Planejamento e de Orçamento Federal, de Administração Financeira Federal, de Contabilidade Federal e de Controle Interno do Poder Executivo Federal, e dá outras providências. Diário Oficial da União, Brasília, 7 fevereiro 2001. Disponível em: $<$ http://www.planalto.gov.br/ccivil_03/LEIS/LEIS_2001/L10180.htm>. Acesso em: $01 \mathrm{abr}$. 2020. 
BRASIL. Lei no 11.892, de 29 de dezembro de 2008. Institui a Rede Federal de Educação Profissional, Científica e Tecnológica, cria os Institutos Federais de Educação, Ciência e Tecnologia, e dá outras providências. Disponível em: $<$ http://www.planalto.gov.br/ccivil_03/_Ato2007-2010/2008/Lei/L11892.htm> . Acesso em: 02 abr. 2020.

BRASIL. Decreto no 6976, de 7 de outubro de 2009. Dispõe sobre o Sistema de Contabilidade Federal e dá outras providências. Diário Oficial da União, Brasília, 8 outubro 2009. Disponível em: <http://www.planalto.gov.br/ccivil_03/_Ato2007-

2010/2009/Decreto/D6976.htm>. Acesso em: 01 abr. 2020.

BRASIL. Ministério da Fazenda. Secretaria do Tesouro Nacional. Portaria $\mathbf{n}^{\mathbf{0}}$ 157, de 9 de março de 2011. Dispõe sobre a criação do Sistema de Custos do Governo Federal. Disponível em: $<$ http://www.fazenda.gov.br/pmimf/frentes-de-atuacao/custos/download-dearquivos/portstn_157_09mar2011.pdf $>$. Acesso em: 01 abr. 2020.

BRASIL. Emenda Constitucional $\mathbf{n}^{0}$ 95, de 15 de dezembro de 2016. Altera o Ato das Disposições Constitucionais Transitórias, para instituir o Novo Regime Fiscal, e dá outras providências. Diário Oficial da União, Brasília, 15 dezembro 2016. Disponível em: $<$ http://www.planalto.gov.br/ccivil_03/constituicao/Emendas/Emc/emc95.htm> Acesso em: 26 mar. 2020.

BRASIL. Ministério da Fazenda. Secretaria do Tesouro Nacional. Manual de Informações de Custos do Governo Federal. Contabilidade de Custos Aplicada ao Setor Público. Aplicado aos Órgãos e Entidades da Administração Pública Federal. Aprovado pela Portaria STN n ${ }^{\circ}$ 518/2018. $1^{\text {a }}$ Edição, 2018. Disponível em:

$<$ https://sisweb.tesouro.gov.br/apex/f?p=2501:9::::9:P9_ID_PUBLICACAO:25901>. Acesso em: 01 abr. 2020.

BRYSON, J. M. A strategic planning process for public and non-profit organizations. Long Range Planning, p. 73-81, vol. 21, 1 ed. 1988. Disponível em:

$<$ https://doi.org/10.1016/0024-6301(88)90061-1>. Acesso em: 26 mar. 2020.

BRYSON, J. M. Strategic planning for public and nonprofit organizations: a guide to strengthening and sustaining organizational achievement. $3^{\text {a }}$ Edição. San Francisco, CA: Jossey-Bass Publishers, 2004.

BRYSON, J. M.; ANDERSON, S. R.; ALSTON, F. K. Implementing and Sustaining Your Strategic Plan: A Workbook for Public and Nonprofit Organizations. 1. ed. San Francisco, CA: Jossey Bass, 2011.

CONSELHO FEDERAL DE CONTABILIDADE. Resolução CFC n 1366, de 25 de novembro de 2011. Aprova a NBC T 16.11 - Sistema de Informação de Custos do Setor Público. Disponível em: $<$ http://www1.cfc.org.br/sisweb/SRE/docs/RES_1366.pdf $>$. Acesso em: 07 abr. 2020.

CHANDLER, A. D. Strategy and Structure: Chapters in the History of the American Industrial Enterprise. Cambridge, MA: The MIT Press, 1962. Disponível em: 
$<$ https://archive.org/details/strategystructur00chan_0> Acesso em: 26 mar. 2020.

DIAMOND, J. Do orçamento por programas para o orçamento de desempenho: o desafio para economias de mercado emergentes. In: GIACOMONI, J.; PAGNUSSAT, J. L. (Org.)

Planejamento e orçamento governamental. Coletânea - v. 2. Brasília: ENAP, 2006.

GIACOMONI, J. Orçamento Público. 17. ed. revisada e atualizada. São Paulo: Atlas, 2017.

INSTITUTO FEDERAL CATARINENSE. Planejamento Estratégico IFC 2018 - 2021. 2018a. Disponível em: <http://ifc.edu.br/wp-content/uploads/2018/11/Vers\%C3\%A3oweb_Planejamento-estrat\%C3\%A9gico-2018-2021CC-2.pdf> Acesso em: 02 abr. 2020.

INSTITUTO FEDERAL CATARINENSE. Regimento Geral. 2018b. Disponível em: $<$ http://ifc.edu.br/wp-content/uploads/2019/02/Regimento-Geral.pdf $>$ Acesso em: 02 abr. 2020 .

INSTITUTO FEDERAL CATARINENSE. Relatório de Gestão do exercício de 2017. 2018c. Disponível em: http://ifc.edu.br/wp-content/uploads/2018/07/Relat\%C3\%B3rio-deGest\%C3\%A3o-2017.pdf Acesso em: 02 abr. 2020.

INSTITUTO FEDERAL CATARINENSE. Relatório de Gestão 2018. 2019a. Disponível em: http://ifc.edu.br/wp-content/uploads/2019/06/Instituto-Federal-Catarinense-Relatorio-deGestao-2018-2.pdf Acesso em: 02 abr. 2020.

INSTITUTO FEDERAL CATARINENSE. PDI - Plano de Desenvolvimento Institucional 2019/2023. 2019b. Disponível em: $<$ http://consuper.ifc.edu.br/wpcontent/uploads/sites/14/2019/01/PDI_2019-2023_VERSO_FINAL_07.06.2019__ps_Consuper.pdf> Acesso em: 02 abr. 2020.

INSTITUTO FEDERAL CATARINENSE. Status Planejamento Estratégico. Disponível em: <http://ifc.edu.br/planejamento-estrategico-2/> Acesso em: 02 abr. 2020.

INSTITUTO FEDERAL CATARINENSE. Planos Operacionais. Disponível em: $<$ http://ifc.edu.br/planejamento-estrategico-2/> Acesso em: 02 abr. 2020.

KAPLAN, R. S.; NORTON, D. P. A estratégia em ação: balanced scorecard. Rio de Janeiro: Elsevier, 1997.

KOHAMA, H. Contabilidade pública: teoria e prática. 14. ed. São Paulo: Atlas, 2014.

LUCAS, A. R. O. Planejamento para aperfeiçoar a gestão de recursos do IFBA Campus Camaçari. 2015. 96 f. Dissertação (Mestrado Profissional em Administração) Universidade Federal da Bahia, Escola de Administração, Salvador, BA, 2015. Disponível em:

$<$ https://repositorio.ufba.br/ri/bitstream/ri/18763/1/Antonio\%20Rubens\%20Oliveira\%20Luca s.pdf> Acesso em: 01 abr. 2020.

MANCINI, B. Orçamento-programa: alguns desafios para sua efetividade no Brasil. In: 
PIRES, V.; SATHLER, A. R. (Org.) Gestão orçamentária inovadora: desafios e perspectivas no Brasil. Brasília: Senado Federal, Coordenação de Edições Técnicas, 2018. Disponível em:

$<$ https://www2.senado.leg.br/bdsf/bitstream/handle/id/553045/gestao_inovadora.pdf $>$. Acesso em: 26 mar. 2020.

MARTINS, E. Contabilidade de custos. 9. ed. São Paulo: Atlas, 2008.

MATUS, C. Adeus, senhor Presidente. Governantes governados. São Paulo: Edições Fundap, 1996.

MATUS, C. O plano como aposta. In: GIACOMONI, J.; PAGNUSSAT, J. L. (Org.) Planejamento e orçamento governamental. Coletânea - v. 1. Brasília: ENAP, 2006. Disponível em:

$<$ https://repositorio.enap.gov.br/bitstream/1/805/1/Colet\%C3\%A2nea\%20Planejamento\%20e $\% 20$ Or $\%$ C3\%A7amento\%20-\%20O\%20plano\%20como\%20aposta.pdf> Acesso em: 26 mar. 2020.

MEDEIROS, A. L. de; CERQUEIRA, E. da S.; NETO, L. A. C. Implantação de Gestão de Custos na Universidade Federal do Tocantins: limites e desafios. In: NUNES, E. B. L. de L. P.; NUNES, C. M. T. P. (Org.) Administração Pública com ênfase em Gestão

Universitária. Coletânea. Palmas: Universidade Federal do Tocantins, 2014.

MINTZBERG, H. Ascensão e queda do planejamento estratégico. Porto Alegre: Bookman, 2004.

MINTZBERG, H.; AHLSTRAND, B.; LAMPEL, J. Safári de Estratégia: um roteiro pela selva do planejamento estratégico. 2. ed. Porto Alegre: Bookman, 2010.

NIVEN, P. R. Balanced Scorecard passo-a-passo: elevando o desempenho e mantendo resultados. Rio de Janeiro: Qualitymark, 2005.

RAUPP, F. M. Gestão de custos no Legislativo municipal por meio do custeio por absorção: um estudo de caso. Pensar Contábil, Rio de Janeiro, v. 11, n. 43, p. 5-14, 2009. Disponível em: $<\mathrm{http}: / / \mathrm{www}$.atena.org.br/revista/ojs-2.2.3-

06/index.php/pensarcontabil/article/view/81> . Acesso em: 26 mar. 2020.

RING, P. S.; PERRY, J. L. Strategic management in public and private organizations: Implications of distinctive contexts and constraints. Academy of Management Review, p. 276-286, vol. 10, $\mathrm{n}^{\circ}$ 2, 1985. Disponível em: <https://doi.org/10.5465/amr.1985.4278197>. Acesso em: 26 mar. 2020.

SANTOS, G. K. dos; RAUPP, F. M.; SECCHI, L. Usos e limitações da gestão de custos no Setor Público: evidências baseadas na percepção dos gestores e contadores do Poder Executivo de Santa Catarina. In: PIRES, V.; SATHLER, A. R. (Org.) Gestão orçamentária inovadora: desafios e perspectivas no Brasil. Brasília: Senado Federal, Coordenação de Edições Técnicas, 2018. Disponível em:

$<$ https://www2.senado.leg.br/bdsf/bitstream/handle/id/553045/gestao_inovadora.pdf $>$. Acesso em: 26 mar. 2020. 